expectation of semi-independent community placement and that a further third could do well provided that adequate support was provided for them in the community. The provision of adequate postdischarge care of the chronic in-patient population requires assessment of their dependency needs, as in the present study. A large number of patients demonstrated significant morbidity and planning for community care must take account of the levels of functioning that such patients can be expected to achieve and the high level of ongoing psychiatric and social care which community services will be required to provide. If these patients' handicaps are not adequately addressed, then community care runs the risk of falling into disrepute. This is particularly important given that, currently, public opinion seems to be divided as to the merits of community care.

\section{Acknowledgements}

The authors would like to thank Dr J. Robertson and Dr Hazel Nelson for their advice, and the nurs- ing staff of Horton Hospital for completing the assessments.

\section{References}

Carson, J., Shaw, L. \& Willis, W. (1989) Which patients first: a study of the closure of a large mental hospital. Health Trends, 21, 117-120.

Curson, D. A., PATEl, M., Liddle, P. F. \& BArnes, T. R. E. (1988) Psychiatric morbidity of a long stay hospital population with chronic schizophrenia and implications for future community care. British Medical Journal, 297, 819-822.

OWENS, D. G. C. \& Johnstone, E. C. (1980) The disabilities of chronic schizophrenia - their nature and the factors contributing to their development. British Journal of Psychiatry, 136, 384-395.

Thornicroft, G. \& Bebbington, P. (1989) Deinstitutionalisation - from hospital closure to service development. British Journal of Psychiatry, 155, 739-753.

A full list of references and details of statistical analyses are available on request to Dr Milne.

\title{
The homeless and the mental health services: a Liverpool study
}

\author{
J. Ferran, Registrar in Psychiatry, Sefton General Hospital, Liverpool L15 2HE; \\ B. O'SHEA, Registrar in Psychiatry, Brighton General Hospital BN2 3EW; and \\ I. A. DAvidson, Consultant Psychiatrist, Royal Liverpool University Hospital L7 8XP
}

It is well known that there is a high prevalence of psychiatric disorder among residents in hostels for the homeless (Timms \& Fry, 1989), and staff in these hostels are looking after the mental health needs of these people sometimes with little help from the institutional services. Recent studies have emphasised the plight of schizophrenia sufferers (Marshall, 1993) while other subgroups of mentally disordered homeless people have received less attention.

This study tries to establish the prevalence of psychiatric morbidity among homeless persons in Liverpool and this was linked with the level of support they received from the statutory services.

\section{The study}

Seven hostels for adult single homeless people in Liverpool were approached within two weeks. These were of small to medium capacity (number of beds ranged from eight to 48), and they constitute the total hostel provision for homeless individuals within Liverpool. Length of stay was limited to three nights in one shelter, to three months in another, and the rest were long-stay hostels, one for women. All persons residing in the hostel on the day of the assessment were invited to participate after details were given about the purpose of the investigation and 
duration of the interview. Strict confidentiality and anonymity were guaranteed, and no payment or other inducement to participate offered. Those under the influence of alcohol were excluded. Personal, social and demographic data were obtained first. To minimise suspiciousness, no names were asked. A psychiatric history was taken, which included information on past and present contact with the psychiatric services, treatment received, and the residents' understanding of the state of their present mental health. Finally, the 60 -item version of the GHQ was administered and those scoring 12 or over were considered as cases.

\section{Findings}

Out of a total of 161 residents, 97 were interviewed, a response rate of $60.2 \%$. Eighty were men and 17 women. Permission was refused by the managers of one hostel on the grounds that asking about suicidal intentions might induce the residents to attempt suicide. Two residents were excluded because they were intoxicated with alcohol. The response rate varied in different hostels: it was highest in the emergency shelter, where each resident agreed to be interviewed $(\mathrm{n}=8)$, and in the other hostels it varied between $73 \%$ and $46 \%$, the lowest figure being for the hostel for women. The mean age of respondents was $\mathbf{4 0}$ years and most were Caucasian and unemployed. One person was married, 63 were single, 18 divorced, nine separated and six widowed. Contrary to findings in London studies, the majority of homeless people in Liverpool originated from this same area (two thirds). The main reported reasons for homelessness were "family problems" (including recent breakdown of relationship), "alcohol and drug problems", and "unemployment". A few of the residents claimed to be voluntarily homeless $(8 \%)$ and mental illness was the reported reason in $6 \%$ of the individuals. The length of homelessness was under six months in nearly half of the residents $(47 \%)$ and the rest had been homeless for a longer period or had had multiple episodes of homelessness.

The overall prevalence of psychiatric morbidity as defined by the GHQ was $54 \%$. According to the psychiatric histories and mental state examinations, $15 \%$ were suffering from schizophrenia, $8 \%$ from affective disorder, $4 \%$ from personality disorder and $21 \%$ from alcohol or illegal drug abuse. Thirty-eight per cent of the respondents considered themselves to be mentally ill at the time of the interview. Twentytwo per cent thought themselves to be mentally ill and also scored as cases according to the GHQ. Within this group, $86 \%$ were considered to be suffering from a psychiatric disorder by the interviewers, mostly alcohol or illegal drug dependence. Of all respondents, $16 \%$ thought themselves mentally ill but did not score as cases according to the GHQ, and
$50 \%$ within this group reported histories consistent with the diagnosis of schizophrenia, but none were thought actively psychotic by the interviewers. Thirty-two per cent of the respondents did not think themselves ill despite scoring as GHQ cases, and $55 \%$ within this group received a psychiatric diagnosis by the interviewers. Only $30 \%$ neither scored as GHQ cases nor thought themselves to be ill, and in this group two individuals ( $7 \%$ ) were deemed mentally ill by the interviewers.

One third of all respondents had had previous psychiatric contact (mostly in-patient care) and $11 \%$ were receiving psychiatric care from a psychiatrist, a CPN, or both. Sixty-eight per cent were registered with a GP, and the hostel staff usually encouraged the residents to join the local GP's list.

Those who both scored positive with the GHQ and thought they were mentally ill were the least supported by statutory services: two thirds received no help and were not even registered with a GP. Within this group, the majority reported having problems with alcohol or illicit drugs $(71 \%)$, the mean age was younger than the average ( 33 years) and most $(70 \%)$ had a short history of homelessness (less than six months). In the residents who thought themselves ill but were not GHQ cases, $62 \%$ had been in contact with the psychiatric services or were currently receiving psychiatric treatment and the level of support was highest in this subgroup: $82 \%$ had regular help from institutional services. These had in general a long history of mental illness and their mean age was older (52) than that for all respondents, and most had a longer history of homelessness (over six months). There was a marked tendency for the newly homeless (homeless for less than six months) to score as positive in the GHQ: in this group $77 \%$ had a positive score against $23 \%$ in the long term group (homeless for over six months).

As regards alcohol and drug dependence, gender differences were noticeable: only $6 \%(n=1)$ of the women presented this problem in contrast to $24 \%$ of the men $(n=19)$.

\section{Comments}

Compared to data published earlier (Timms \& Fry, 1989) the prevalence of psychiatric morbidity detected in our study is lower $(54 \%)$ but still three times higher than the prevalence found in community studies of the general population using the GHQ (Finlay-Jones \& Burvill, 1977). A more recent study of homeless women in London using the same screening instrument found a similar level (Scott, 1991). Perhaps this reflects recent changes in the composition of the homeless population as a result of the current economic climate, but it could also be argued that the prevalence of psychiatric disorder was higher in those who refused to participate. 
It is interesting to observe that the group of residents one would think would be most in need of statutory support were those who were least in contact with the services: only one third of those who both scored as GHQ cases and thought themselves to be ill had some sort of assistance, and this meant in many cases being merely registered with a GP.

Only $15 \%$ were seeing a psychiatrist regularly and a similar proportion a CPN. Some studies have emphasised the lack of support from the psychiatric services of the residents in hostels for the homeless and this survey corroborates it. Interestingly, those who had a history of schizophrenia and previous psychiatric admissions had a good level of support and, in general, did not score as GHQ cases. Only four respondents had been long-term residents in psychiatric institutions, and none had lost contact with the services on discharge. A high GHQ score can be interpreted as indicative of high levels of stress, which in any case would be expected in this population. That they did not score, in general, as cases, is perhaps indicative of lower levels of anxiety or distress and could be attributed to having been homeless for a longer period or having a higher level of support from the services (or both). It could also be argued that the GHQ missed some actively psychotic cases, but this was not confirmed with the psychiatric histories and mental state examinations. Nearly one third of the respondents in this survey did not consider themselves mentally ill despite scoring as GHQ cases, a significant at-risk population unlikely to request assistance from the health services. It appears, from this study, that a subgroup of residents with illegal drug or alcohol problems, usually young and newly homeless, is the one most in need of the services, and as it seems improbable that these individuals will actively seek help, a member of the mental health team could be designated to liaise with the hostels to provide support for these residents and perhaps engage them in treatment.

This liaison member of the team should also play a role in educating hostel managers and staff in mental health issues: the grounds on which permission was refused by the managers of one hostel are noteworthy.

\section{References}

Finlay-Jones, R. A. \& Burvill, D. W. (1977) The prevalence of minor psychiatric morbidity in the community. Psychological Medicine, 7, 475-489.

MARSHALl, M. (1993) Untreated schizophrenia in hostels for the homeless; a cause for concern?. Psychiatric Bulletin, 17, 16-17.

Scort J. (1991) Resettlement units or asylum? Presented to the annual meeting, The Royal College of Psychiatrists.

Timms, P. W. \& FrY, A. H. (1989) Homelessness and mental illness. Health Trends, 21, 70-71.

A full list of references is available on request to Dr Ferran. 